\title{
Pharmaceutical Equivalence of Some Commercial Samples of Artesunate and Amodiaquine Tablets Sold in Southwestern Nigeria
}

\author{
OO Odunfa ${ }^{1}$, OA Adegoke ${ }^{2}$ and IC Onaga ${ }^{1^{\star}}$
}

Departments of ${ }^{1}$ Pharmaceutics and Industrial Pharmacy, and ${ }^{2}$ Pharmaceutical Chemistry, Faculty of Pharmacy, University of Ibadan, Ibadan, Nigeria.

\begin{abstract}
Purpose: To study the physical properties and dissolution profiles of commercial samples of artesunate and amodiaquine tablets.

Methods: Fifteen generic brands of artesunate and five generic brands of amodiaquine tablets were obtained from drug retail outlets in Oyo and Ogun States in southwestern Nigeria. The tablets were subjected to various compendial tests including identification, weight uniformity, uniformity of content, content of active ingredient and uniformity of diameter. Additional tests used as a basis for the assessment of the pharmaceutical equivalence of the products include hardness, disintegration time and dissolution rate. Data obtained were analysed by correlation analysis, Chi-square and ANOVA.

Results: Thirteen generic brands of artesunate $(87 \%)$ and four amodiaquine brands $(80 \%)$ investigated were imported. Two brands of the imported artesunate brands were found to contain undetectable amount of artesunate while another 8 samples contained overages. All the amodiaquine brands passed the assay test as stipulated by United States Pharmacopoeia (USP) for amodiaquine tablets while tablet disintegration time of amodiaquine products ranged from $5.8-20.7 \mathrm{~min}$. All but one artesunate sample passed the disintegration test too. A majority of the artesunate brands tested had significantly different dissolution profiles $(p<0.05)$. Four $(80 \%)$ of the amodiaquine tablet brands tested had similar dissolution profiles and percent drug released within $30 \mathrm{~min}(p>0.05)$. One amodiaquine brand demonstrated poor dissolution profile as it did not meet minimum dissolution requirements within 30 min.

Conclusion: The detection of substandard artesunate tablets and a poorly formulated amodiaquine tablet amongst the few sample brands studied highlights the need for increased drug surveillance and monitoring of the qualities of antimalarial medicines currently in use in order to prevent widespread treatment failure.
\end{abstract}

Keywords: Artesunate tablets; Amodiaquine tablets; Tablet hardness; Disintegration time; Dissolution profile; Pharmaceutical equivalence; Drug surveillance and monitoring. 


\section{INTRODUCTION}

Artemisinin-based therapies are a major breakthrough in the clinical management of malaria. The problem of faking and adulteration of antimalarials may constitute a major hindrance to the attainment of effective drug-based health care delivery. Artesunate is an artemisinin-based antimalarial drug which is indicated in the treatment of acute, uncomplicated, severe and resistant malaria.

By 2006, 39 countries in Africa had revised their national drug policies to incorporate artemisinin combination therapy (ACT) into malaria case-management guidelines [1]. Oral artesunate can be used alone (in nonresistant malaria) or also in combination with other long acting antimalarials such as amodiaquine, mefloquine, sulfadoxine/ pyrimethamine or lumenfantrine to achieve ACT. As a result of the short half-life of artemisinin derivatives, their use as monotherapy requires daily doses over a period of 7 days. Combination of one of these drugs with a longer half-life antimalarial drug allows a reduction in the duration of antimalarial treatment while at the same time enhancing efficacy and reducing the likelihood of resistance development to the two agents [2]. The availability of numerous brands of this artesunate in the Nigerian drug market today places clinicians and pharmacists in a difficult situation of choice of a suitable brand and/or alternatives.

Furthermore, there are growing concerns that the various artesunate formulations may have different bioavailability and that development of resistance will be accelerated if suboptimal doses are consumed [3,4]. Reports of distribution of counterfeit artesunate tablets in south-east Asia are of great public health concern [5]. It is believed that each year, 300500 million people in Asia and Africa are infected with Plasmodium falciparum malaria and approximately 1.5 million die [6]. Control of malaria, which is dependent on effective antimalarial drugs and bed nets, has been hampered by a widespread increase in the prevalence of drug-resistant malaria parasites [7].

As effective as artesunate is, it is becoming the target of an extremely sophisticated and prolific counterfeit drug trade that includes the counterfeiting of both artesunate tablets and packaging, with fake products looking very similar to authentic ones $[8,9]$. The inability of a large section of the populace in resourcelimited countries to afford the relatively more expensive branded products, as well as slack domestic drug law enforcement, are factors in the infiltration of branded artesunate and amodiaquine tablets of doubtful quality. The need, therefore, to monitor the physicochemical and biopharmaceutical qualities of the generic antimalarial agents cannot be over-emphasized. The present study is designed to determine the relative physicochemical quality of the various generic and branded artesunate $(50 \mathrm{mg})$ and amodiaquine (153.1 $\mathrm{mg}$ and $200 \mathrm{mg}$ ) tablets in a section of the Nigerian market in order to ascertain their biopharmaceutical equivalence and their possible interchangeability in clinical use.

\section{EXPERIMENTAL}

\section{Materials}

Artesunate reference powder was a donation from Greenlife Pharmaceuticals Nigeria Plc, (Lagos, Nigeria) and amodiaquine reference powder was donated by Pfizer Specialties Ltd, (Lagos, Nigeria). Sodium hydroxide, hydroxylamine hydrochloride, ethanol, acetone, ethyl acetate, toluene, methanol, ferric chloride (all of analytical reagent grades from BDH, Poole, England); Hardness Tester (BTB 301 Pharmatest, Switzerland); Erweka tablet disintegration apparatus (Erweka, Apparabetau, Germany); Erweka DT-D dissolution test apparatus (Erweka, U.K.); TLC plates (Merck, Germany); UV-VIS spectrophotometer (Hitachi, Japan) were used in this study.

Samples of different brands of artesunate 50 
$\mathrm{mg}$ and amodiaquine $\mathrm{HCl}(153.1 \mathrm{mg}$ and 200 $\mathrm{mg}$ ) tablets were randomly purchased from pharmacy retail outlets in southwestern Nigeria all samples were within their shelf-life. The purchase costs were noted. Fifteen samples that cut across 9 different artesunate brands (designated $A-I$ ) and five different amodiaquine brands (AA, BB, CC, DD, EE) were randomly selected for this study. Randomization was done in the proportion of 50:30:20 (Lagos:Ogun:Oyo states).

\section{Subjective physical assessment of products}

The labels, external packages, unique identification marks, leaflet inserts, foils and tablets were carefully examined for unique markings, odour and colour by all three authors of this work. Decisions were based on agreement among at least two out of the three assessors. For colour assessment, the tablets were placed on a white sheet of paper and both sides of each tablet examined. Identification of the white colour (for artesunate) and yellow colour (for amodiaquine) was carried out by matching with the closest colour in Federal Standard Number 595 colours (10). Deviations from the chosen colours were rated from a scale of 1 10 with 10 being the chosen white and yellow colours and 1 being the highest level of deviation.

The tablets were odourless if they were not flavoured.

\section{Weight uniformity test and Uniformity of diameter}

Evaluation of tablet weight variation was carried out using the weight uniformity test outlined in the British Pharmacopoeia [11]. Twenty tablets were randomly selected for each brand evaluated and their weights determined. The mean weight and deviation (\%) were calculated.

A micrometer screw gauge (SMC 20326,
Sterling Manufacturing Company, India) was used to measure the diameter of 12 randomly selected tablets. The mean diameter and deviation (\%) from the mean were calculated.

Identity test for artesunate and
amodiaquine

Artesunate in the tablets were identified using methods $B, C$ and $D$ of International Pharmacopoeia (IP) [12] based on a validated TLC-Thin Layer Chromatography.

Method B: Silica gel was used as the coating substance and a mixture of 5 volumes of ethyl acetate and 95 volumes of toluene was used as the mobile phase. Solution A was prepared as follows: a quantity of the powdered tablets, equivalent to about $0.1 \mathrm{mg}$ of artesunate, was mixed well with dehydrated ethanol and filtered through a Whatman no. 1 filter paper, discarding the first few $\mathrm{mL}$ of the filtrate. The filtrate was evaporated and the residue dissolved in 1.0 $\mathrm{ml}$ of toluene. Solution B consisted of about $0.1 \mathrm{mg}$ of artesunate RS per $\mathrm{ml}$ of toluene. Two microlitres each of Solutions $A$ and $B$ were spotted on the TLC and developed in the chamber. After removal of plate from the chamber, it was air-dried, sprayed with anisaldehyade methanol TS, and heated to $120{ }^{\circ} \mathrm{C}$ for $5 \mathrm{~min}$. The chromatograms were examined in ultraviolet light at a wavelength of $254 \mathrm{~nm}$ and the $\mathrm{R}_{\mathrm{f}}$ values (distance travelled by spot / distance travelled by solvent front) of the various batches were calculated.

Method C: To a quantity of the powdered tablets equivalent to $0.1 \mathrm{~g}$ of artesunate, 40 $\mathrm{ml}$ of dehydrated ethanol was added, shaken and then filtered through a Whatman no.1 filter paper, discarding the first few $\mathrm{mL}$ of the filtrate. To half of the filtrate, about $0.5 \mathrm{ml}$ of hydroxylamine hydrochloride TS2 and 0.25 $\mathrm{ml}$ of $\mathrm{NaOH}(\sim 80 \mathrm{~g} / \mathrm{L})$ TS were added. The mixture was heated in a water bath to boiling, cooled and two drops of $\mathrm{HCl}(\sim 70 \mathrm{~g} / \mathrm{L})$ TS and two drops of ferric chloride $(50 \mathrm{~g} / \mathrm{L})$ TS was added. 
Method D: The remaining filtrate in Method C was evaporated on a water bath to a volume of about $5 \mathrm{ml}$. Few drops of the mixture was placed on a white porcelain dish and one drop of vanillin/sulphuric acid TS2 was added and allowed to stand for $30 \mathrm{~min}$.

A sample that contains artesunate yields a principal spot on TLC with the same $R_{f}$, appearance and intensity as the reference artesunate (method A), a light red-violet colour (method B) and a red colour (method D). Failure to yield these results constitutes a negative result.

Amodiaquine was identified using United States Pharmacopoeia (USP) method B (UVVIS absorption) [13] whereby an amount equivalent to $300 \mathrm{mg}$ of amodiaquine was transferred to a $250 \mathrm{ml}$ beaker. $100 \mathrm{ml}$ of dilute hydrochloric acid (1 in 100) was added and heated on a steam bath for about $15 \mathrm{~min}$ with occasional stirring. The mixture was cooled to room temperature and transferred to a $200 \mathrm{ml}$ volumetric flask. Dilute hydrochloric acid (1 in100) was added to make it up to $200 \mathrm{ml}$ and mixed; $10 \mathrm{ml}$ of the clear supernatant was mixed with $10 \mathrm{ml}$ of dilute hydrochloric acid (1 in 100) in a $125 \mathrm{ml}$ separator. It was washed with $20 \mathrm{ml}$ of chloroform, the washing discarded, and $4.5 \mathrm{ml}$ of $1 \mathrm{~N}$ sodium hydroxide was added followed by extraction with four $25 \mathrm{ml}$ portions of chloroform. The combined chloroform extract portions were further extracted with three 50 $\mathrm{ml}$ portions of dilute hydrochloric acid (1 in 100). The acid extracts were combined in a $200 \mathrm{ml}$ volumetric flask, dilute hydrochloric acid (1 in 100) was added to volume and mixed. A portion $(20 \mathrm{ml})$ of this solution was mixed with dilute hydrochloric acid (1 in 100) and made up to volume with the latter in a $100 \mathrm{ml}$ volumetric flask. The absorbance of this solution was concomitantly determined with a solution of the undried amodiaquine reference sample in dilute hydrochloric acid (1 in 100) having a known concentration of 15 $\mu \mathrm{g}$ per $\mathrm{ml}$ in $1 \mathrm{~cm}$ cells at $342 \mathrm{~nm}$ with ultraviolet spectrophotometer (Hitachi, Japan) using dilute hydrochloric acid (1 in 100) as blank.

\section{Assay of artesunate and amodiaquine tablets}

Artesunate tablets were analysed for their content of artesunate using titrimetric procedure B of IP [12] whereby $50 \mathrm{ml}$ of neutralized ethanol (ethanol $~ 750 \mathrm{~g} / \mathrm{L}$ containing $0.5 \mathrm{~mL}$ of phenolphthalein and carbonate-free $0.1 \mathrm{~mol} / \mathrm{l}$ sodium hydroxide and shows a faint pink colour) was mixed well with a quantity of crushed artesunate tablets equivalent to $0.5 \mathrm{~g}$ of artesunate and the filtrate titrated against sodium hydroxide.

For the amodiaquine assay, the USP spectrophotometric procedure (method B for identity test described above) was used. Six replicate determinations were carried out. The quantity in $\mathrm{mg}$, $\mathrm{W}$, of amodiaquine hydrochloride present was calculated in the portion of tablets taken by the formula:

$\mathrm{W}=21.68 \mathrm{C}(\mathrm{Au} / \mathrm{As})$

where $\mathrm{C}=$ concentration in $\mu \mathrm{g}$ per $\mathrm{ml}$ (calculated on anhydrous basis) of the reference sample; and $\mathrm{Au}$ and

As are the absorbances of the solution obtained from the tablets and the standard solution, respectively.

\section{Hardness and disintegration tests}

BTB 301 hardness tester was employed. 10 tablets per sample/brand were used for the test and mean hardness values $(\mathrm{KgF})$ were recorded. For the disintegration test, the disintegration time of six tablets per batch/brand were determined in distilled water maintained at $37 \pm 0.5{ }^{\circ} \mathrm{C}$ using Erweka tablet disintegration apparatus, and the mean values calculated.

\section{Dissolution test}

Dissolution tests were carried out on the tablets using the USP general method [13] in 
$0.1 \mathrm{M} \mathrm{HCl}(900 \mathrm{ml})$ with the aid of Erweka DT-D dissolution test apparatus (Erweka, U.K.) fitted with a basket rotated at $100 \mathrm{rpm}$ for artesunate tablets and $50 \mathrm{rpm}$ for amodiaquine tablets as prescribed by IP [12] and USP [13], respectively. Samples were withdrawn from a zone midway between the surface of the dissolution medium and the top of the rotating basket, and replaced with fresh aliquot of dissolution medium, in order to maintain sink conditions.

The samples were filtered and diluted appropriately with $0.1 \mathrm{~N} \mathrm{HCl}$ and water for artesunate and amodiaquine, respectively. The absorbance of the solutions were measured at $216 \mathrm{~nm}$ and $342 \mathrm{~nm}$, respectively. Drug released (\%) against time was plotted for each formulation and the $t_{50}$ and $t_{75}$ (time required for $50 \%$ and $75 \%$ of drug dissolution, respectively) were deriveded from the plots by extrapolation. The amount dissolved in 45 and 30 min was obtained for each brand of artesunate and amodiaquine, respectively. All determinations were in quadruplicate.

\section{Data analysis}

Chi square was used to analyse the effect of cost of product brand on quality. Correlation analysis was adopted to study the interrelationship between various physical parameters while the dissolution data were analysed using ANOVA. Results are expressed as mean \pm sd of four determinations.

\section{RESULTS}

\section{Physical and organoleptic properties}

The results of physical and organoleptic assessment of the label, packaging, etc, of artesunate products, Table 1 , indicate that they were attractively packaged with unique identification markings, except samples B2 and B3 which were poorly packaged and had a dull green colour. All the artesunate samples were marked with the logo and/or brand name of their claimed manufacturer. The tablets were odourless with colours ranging from white to off-white or a tint of yellow. As Table 2 shows, all the amodiaquine products were attractively packaged; the tablets were yellow in colour, scored and also marked with the manufacturer's logo, with the exception of sample DD which had no unique logo and was not scored. These physical observations indicate that all the artesunate tablets, except B2, B3 and DD, were satisfactory in appearance with actual identification marks

Based on Table 1, thirteen out of the total of 15 samples of the artesunate brands studied contained artesunate in conformity with International Pharmacopeia (IP) requirements, except B2 and B3 which contained < $50 \%$ of labelled content. All the artesunate brands passed the weight uniformity test as no two tablets deviated by more than $10 \%$ and none by $20 \%$. Furthermore, all the artesunate tablets had mean diameter within the IP limit, and also showed good hardness. Five (33\%) of the artesunate tablet samples contained artesunate within IP range (90 $110 \%)$ of label claim, $8(53.3 \%)$ exceeded the upper limit (> $110 \%$ ) and 2 brands, B2 and B3, (13.3\%) fell well below the lower limit.

The unit cost per packet was similar for the artesunate products with the substandard products costing about as much as the genuine ones. There was no statistically significant difference $(p>0.05)$ in cost between imported and locally manufactured tablets. All amodiaquine tablets had satisfactory physical and organoleptic properties.

\section{Physicochemical properties}

Table 2 shows the physicochemical properties of amodiaquine tablet brands. All 5 brands of amodiaquine tablets showed good hardness properties and met USP drug content requirements of $93-107 \%$ of labelled content [13]. The cost per unit packet of amodiaquine varied much more than that of artesunate tablets, with the latter being more expensive. 
Table 1: Physicochemical properties artesunate tablets

\begin{tabular}{|c|c|c|c|c|c|c|c|c|c|}
\hline Code & $\begin{array}{l}\text { Product } \\
\text { appearance }\end{array}$ & $\begin{array}{l}\text { Content } \\
\text { uniformity }\end{array}$ & $\begin{array}{l}{ }^{\mathrm{a}} \text { Artesunate } \\
\text { content (\%) }\end{array}$ & $\begin{array}{l}\text { Cost/ } \\
\text { pack } \\
\text { of } 12 \\
\text { tablets } \\
\text { (US \$) }\end{array}$ & $\begin{array}{l}\text { Diameter } \\
(\mathrm{mm})^{b}\end{array}$ & $\begin{array}{l}\text { Hard- } \\
\text { ness } \\
(\mathrm{KgF})^{\mathrm{c}}\end{array}$ & $\begin{array}{l}\text { Expiry } \\
\text { date }\end{array}$ & Brand & $\begin{array}{l}\text { Country of } \\
\text { Manufac- } \\
\text { ture }\end{array}$ \\
\hline$A$ & Satisfactory & 54.0 & $108.1 \pm 1.4$ & 2.2 & $9.5 \pm 0.0$ & $5.2 \pm 0.6$ & $09 / 08$ & Aretmed & India \\
\hline B & Satisfactory & 59.1 & $118.3 \pm 1.6$ & 2.3 & $10.2 \pm 0.0$ & $5.4 \pm 0.6$ & $12 / 09$ & Artesunat & China \\
\hline B1 & Satisfactory & 56.7 & $113.5 \pm 1.4$ & 2.3 & $10.1 \pm 0.0$ & $5.6 \pm 0.9$ & $03 / 10$ & Artesunat & China \\
\hline B2 & unsatisfactory & 14.2 & $28.3 \pm 1.6$ & 2.3 & $10.2 \pm 0.0$ & $6.6 \pm 1.9$ & 08/08 & Artesunat & China \\
\hline B3 & unsatisfactory & 24.8 & $49.5 \pm 3.4$ & 2.3 & $10.2 \pm 0.0$ & $6.9 \pm 1.9$ & $07 / 09$ & Artesunat & China \\
\hline C & Satisfactory & 53.0 & $106.1 \pm 2.2$ & 2.5 & $9.5 \pm 0.0$ & $7.7 \pm 0.4$ & $10 / 08$ & Arthlon & India \\
\hline D & Satisfactory & 54.4 & $108.8 \pm 2.2$ & 2.4 & $10.6 \pm 0.0$ & $3.8 \pm 0.4$ & $11 / 09$ & Malasunate & China \\
\hline E & Satisfactory & 53.7 & $107.4 \pm 1.6$ & 2.0 & $8.7 \pm 0.1$ & $8.1 \pm 1.5$ & $07 / 08$ & Arinate & Belgium \\
\hline $\mathrm{F}$ & Satisfactory & 56.1 & $112.1 \pm 2.6$ & 2.4 & $9.5 \pm 0.0$ & $5.5 \pm 2.8$ & 09/09 & Vami's & Nigeria \\
\hline $\mathrm{F} 1$ & Satisfactory & 56.4 & $112.8 \pm 2.7$ & 2.4 & $9.5 \pm 0.0$ & $5.3 \pm 0.9$ & $02 / 10$ & Vami's & Nigeria \\
\hline$G$ & Satisfactory & 56.1 & $112.1 \pm 2.6$ & 2.2 & $9.5 \pm 0.0$ & $5.5 \pm 1.5$ & 09/08 & Lever & China \\
\hline G1 & Satisfactory & 57.4 & $114.8 \pm 1.4$ & 2.1 & $9.3 \pm 0.0$ & $5.5 \pm 1.3$ & $11 / 09$ & Lever & China \\
\hline $\mathrm{H}$ & Satisfactory & 55.4 & $110.8 \pm 2.6$ & 2.4 & $9.2 \pm 0.0$ & $4.2 \pm 1.1$ & $05 / 08$ & Malmeter & India \\
\hline $\mathrm{H} 1$ & Satisfactory & 54.0 & $108.1 \pm 2.6$ & 2.4 & $9.1 \pm 0.0$ & $4.3 \pm 0.9$ & $09 / 08$ & Malmeter & India \\
\hline I & Satisfactory & 57.1 & $114.2 \pm 2.2$ & 2.5 & $9.6 \pm 0.01$ & $5.2 \pm 0.5$ & $12 / 08$ & Larimal & India \\
\hline
\end{tabular}

aIP requirement: $90-110 \%$ of amount stated on label $(n=6) ;{ }^{b} n=12 ;{ }^{c} n=10$

Table 2: Physicochemical properties of amodiaquine tablets

\begin{tabular}{lllllllllll}
\hline Code & $\begin{array}{l}\text { Drug } \\
\text { content } \\
(\%)\end{array}$ & $\begin{array}{l}\mathrm{t}_{\mathrm{d}} \\
(\mathrm{min})^{\mathrm{b}}\end{array}$ & $\begin{array}{l}\text { Drug } \\
\text { rel }(\%) \\
30 \mathrm{~min}^{\mathrm{b}}\end{array}$ & $\begin{array}{l}\mathrm{t}_{50} \\
(\mathrm{~min})\end{array}$ & $\begin{array}{l}\mathrm{t}_{55} \\
(\mathrm{~min})\end{array}$ & $\begin{array}{l}\text { Hardness } \\
(\mathrm{KgF})^{d}\end{array}$ & $\begin{array}{l}\text { Unit cost } \\
\text { per tablet } \\
(\mathrm{US} \$)\end{array}$ & $\begin{array}{l}\text { Expiry } \\
\text { date }\end{array}$ & $\begin{array}{l}\text { Brand } \\
\text { Country of } \\
\text { manufacture }\end{array}$ \\
\hline AA & $94.3 \pm 0.3$ & $9.2 \pm 0.8$ & $81.2 \pm 1.8$ & $3.7 \pm 0.1$ & $4.8 \pm 0.5$ & $4.8 \pm 0.4$ & 0.5 & $12 / 09$ & Camoquine & USA \\
BB & $94.0 \pm 0.5$ & $5.8 \pm 0.4$ & $82.8 \pm 1.3$ & $3.2 \pm 0.1$ & $5.1 \pm 0.2$ & $6.4 \pm 0.8$ & 0.3 & $12 / 08$ & Larimal & India \\
CC & $94.6 \pm 0.4$ & $9.0 \pm 0.6$ & $73.3 \pm 2.0$ & $5.0 \pm 1.0$ & $31.7 \pm 1.3$ & $4.9 \pm 0.4$ & 0.2 & $12 / 09$ & Timec & India \\
DD & $94.4 \pm 0.9$ & $20.7 \pm 0.8$ & $82.8 \pm 3.8$ & $3.4 \pm 0.1$ & $5.9 \pm 1.0$ & $4.4 \pm 0.7$ & 0.4 & $10 / 08$ & Loquine & England \\
EE & $94.6 \pm 1.0$ & $15.8 \pm 1.8$ & $81.3 \pm 3.9$ & $3.2 \pm 0.1$ & $6.2 \pm 0.9$ & $4.8 \pm 1.0$ & 0.6 & $3 / 09$ & Dart & Nigeria \\
\hline
\end{tabular}

${ }^{a}$ USP requirement: $93-107 \%$ of amount stated on label $(n=6) ;{ }^{b} n=6{ }^{d} n=10 ; t_{d}=$ disintegration time; $t_{50}=$ time taken to attain $50 \%$ dissolution; $t_{75}=$ time taken to attain $75 \%$ dissolution. All brands had satisfactory product appearance

Artesunate tablets disintegrated within $12 \mathrm{~min}$ with the exception of brand $\mathrm{B} 2$, one of the two substandard samples, which disintegrated in $34.8 \mathrm{~min}$; this is higher than the official USP limit of 30 min. However, all the brands of amodiaquine tablets disintegrated within 21 min which is within the USP limit of $30 \mathrm{~min}$. The $t_{50}$ and $t_{75}$ (USP upper limits of $t_{50}$ and $t_{75}$ are 20 and $30 \mathrm{~min}$, respectively, beyond which dissolution is poor) dissolution values indicate that all the tablets also possess good dissolution properties except amodiaquine brand CC which did not meet the essential minimum within $30 \mathrm{~min}$ (Figure 3 ). In addition, the amodiaquine brands passed drug identification test, as shown in Table 2. 
Odunfa et al

Table 3: Disintegration and dissolution parameters for artesunate tablets $(n=6)$

\begin{tabular}{lllll}
\hline Code & $\begin{array}{l}\text { Disintegration } \\
\text { time (mins) }\end{array}$ & $\mathrm{t}_{50}(\mathrm{~min})^{\mathrm{a}}$ & $\mathrm{t}_{75}(\mathrm{~min})^{\mathrm{a}}$ & $\begin{array}{l}\text { Dissolution in } \\
45 \mathrm{~min}(\%)\end{array}$ \\
\hline $\mathrm{A}$ & $3.8 \pm 0.8$ & $2.9 \pm 0.1$ & $3.9 \pm 0.1$ & $79.0 \pm 1.0$ \\
$\mathrm{~B}$ & $3.5 \pm 0.5$ & $3.0 \pm 0.1$ & $4.0 \pm 0.1$ & $89.0 \pm 0.9$ \\
$\mathrm{~B} 1$ & $3.3 \pm 1.0$ & $3.0 \pm 0.1$ & $4.0 \pm 0.1$ & $93.0 \pm 1.1$ \\
$\mathrm{~B} 2$ & $34.8 \pm 3.3$ & - & - & - \\
$\mathrm{B} 3$ & $3.8 \pm 0.8$ & - & - & - \\
$\mathrm{C}$ & $4.2 \pm 0.8$ & $2.9 \pm 0.1$ & $3.9 \pm 0.1$ & $81.0 \pm 1.4$ \\
$\mathrm{D}$ & $3.8 \pm 0.8$ & $2.7 \pm 0.1$ & $3.3 \pm 0.2$ & $92.0 \pm 1.2$ \\
$\mathrm{E}$ & $3.0 \pm 0.6$ & $3.0 \pm 0.1$ & $4.1 \pm 0.1$ & $79.0 \pm 1.1$ \\
$\mathrm{~F}$ & $7.7 \pm 1.2$ & $2.9 \pm 0.2$ & $3.8 \pm 0.2$ & $93.00 \pm 1.5$ \\
$\mathrm{~F} 1$ & $11.7 \pm 2.0$ & $2.9 \pm 0.2$ & $3.9 \pm 0.1$ & $95.0 \pm 5.5$ \\
$\mathrm{G}$ & $3.5 \pm 0.8$ & $2.8 \pm 0.2$ & $3.6 \pm 0.3$ & $89.0 \pm 0.9$ \\
G1 & $3.5 \pm 0.8$ & $2.8 \pm 0.2$ & $3.6 \pm 0.2$ & $88.0 \pm 0.8$ \\
$\mathrm{H}$ & $4.8 \pm 0.8$ & $2.8 \pm 0.3$ & $3.8+/-0.2$ & $84.0 \pm 0.6$ \\
$\mathrm{H} 1$ & $7.7 \pm 0.8$ & $2.9 \pm 0.1$ & $4.0 \pm 0.2$ & $85.0 \pm 1.4$ \\
$\mathrm{I}$ & $4.2 \pm 0.8$ & $2.9 \pm 0.1$ & $3.9 \pm 0.1$ & $84.0 \pm 0.8$ \\
\hline
\end{tabular}

${ }^{a} n=6 ;{ }^{b} n=6 ; t_{50}=$ time taken to attain $50 \%$ diccolı ıtinn $\cdot t_{\rightarrow r}-$ time taken to attain $75 \%$ diccolı tion
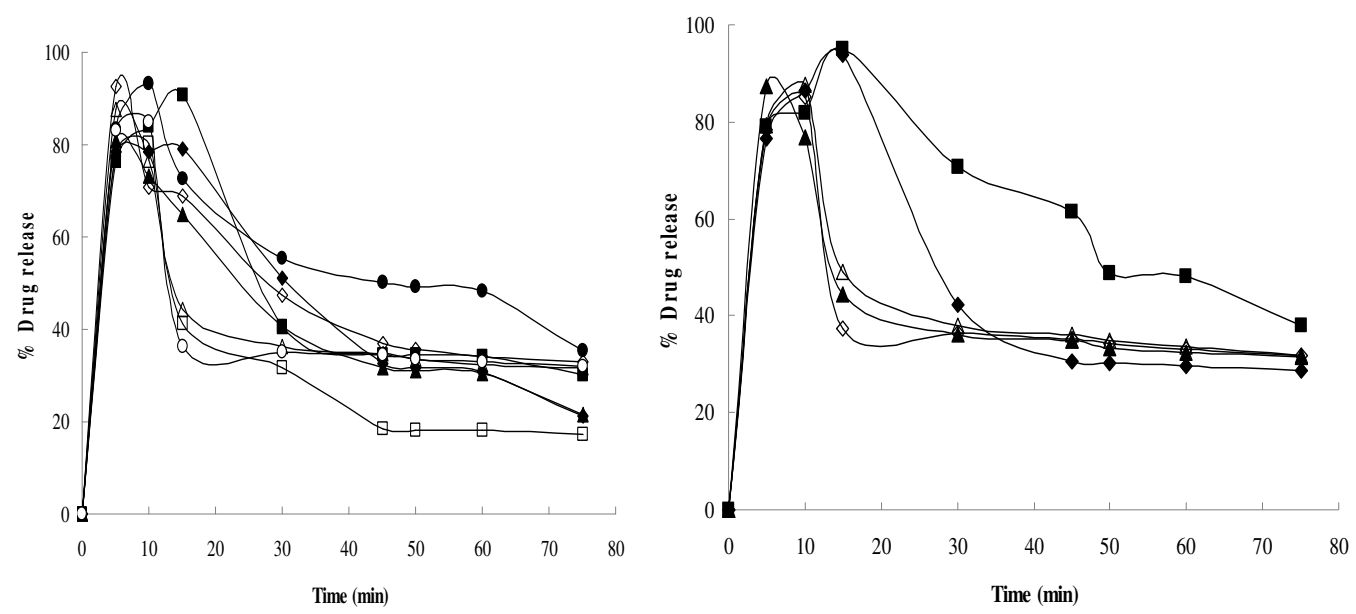

Figure 1: Dissolution profiles of artesunate tablet brands. (a): $\bullet=A ; \boldsymbol{\square}=\mathrm{B} ; \boldsymbol{\Delta}=\mathrm{C} ; \diamond=\mathrm{D} ; \square=\mathrm{E} ; \boldsymbol{\bullet}=\mathrm{F}$; $\triangle=\mathrm{G} ; \mathrm{O}=\mathrm{H} ;$ and $(\mathrm{b}): \triangle=\mathrm{I} ; \diamond=\mathrm{B} 1 ; \boldsymbol{\nabla}=\mathrm{F} 1 ; \boldsymbol{\Delta}=\mathrm{G} 1 ; \diamond=\mathrm{H} 1$

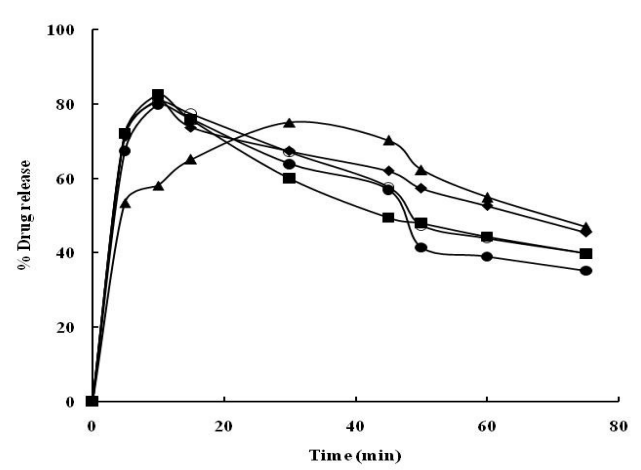

Figure 2: Dissolution profiles of amodiaquine tablet brands: $\mathrm{O}=\mathrm{AA} ; \mathbf{\square}=\mathrm{BB} ; \mathbf{\Delta}=\mathrm{CC} ; \bullet=\mathrm{DD}$; $=\mathrm{EE}$

\section{DISCUSSION}

\section{Artesunate products}

The results presented in Table 1 indicate that a majority $(66.7 \%)$ of the artesunate tablets studied failed the drug content assay test. The identification test (using TLC) revealed that artesunate was undetectable in brands B2 and B3, due probably to the low content of drug. The packaging of the fake products was similar to some of the genuine brand, except for their colour and unique markings. This suggests that they might have been 
deliberately counterfeited. Counterfeiting has been reported in a recent survey in southeast Asia which showed that among 104 tablet brands presented as artesunate, $38 \%$ did not contain artesunate. Magnus et al [14] stated in a previous study that counterfeit or substandard artemisinin-based derivatives were being sold in parts of Africa, presenting a potential route for resistance development in the future. Also in Cambodia in 1990, substandard antimalarials were reported as responsible for the deaths of at least 30 people [15]. The results from this work are the first to show, to the best of our knowledge, the circulation of substandard artesunate tablet in Nigeria. This poses a serious health danger as Nigeria, in 2004, adopted the use of ACTs, in her national antimalarial treatment policy, for uncomplicated malaria in accordance with WHO guidelines [16]. In view of the health implications of counterfeit products, including development of resistant strains of plasmodium parasites, this calls for proper monitoring of all commercial brands of artesunate tablets, both locally manufactured and imported, including at ports of entry for imported products.

Out of the 10 generic products $(66.7 \%)$ that failed drug content test, 8 were imported products and $2(20 \%)$ were locally manufactured ( $F$ and $F_{1}$ ) as shown in Table 1. Eight out of these 10 products had excess drug (> $110 \%$ of labelled content) and although they may be therapeutically effective, there could be increased risk of toxicity and increased side-effects on ingestion. The two products with drug content below pharmacopoeial specifications may be regarded as substandard and/or counterfeit products.

Chi-square analysis of the unit cost of the products and physicochemical properties revealed that there is no significant correlation between cost and the quality of artesunate products $(p=0.449)$ or between the quality of the drug and country of manufacture $(p=0.364)$.
In the dissolution test, at $45 \mathrm{~min}$, all the artesunate products, except B2 and B3 which failed the drug content test, released over 75 $\%$ of their drug content (see Table 3, Figure 1) and thus satisfied the requirements of $B P$ [17] which states that the amount of active ingredient released in solution for uncoated tablets at 45 min should not be less than 75 $\%$ of the labelled strength.

Products $F$ and $F_{1}$ which are indigenous (local) artesunate tablets had comparable hardness, longer disintegration times and higher amounts of active drug released compared to product $B$ which served as the reference (Tables 1 and 3 ). This indicates good formulation protocol for these local products.

\section{Amodiaquine products}

All the five amodiaquine brand products studied disintegrated within $21 \mathrm{~min}$ (Table 2) and thus complied with the USP limit of 30 min. All the amodiaquine products had good hardness properties. There was no correlation between tablet hardness and disintegration time for these products $(p>$ 0.05). The drug release profile of three of the products (BB, DD and EE) were not statistically different $(p>0.05)$ from that of the reference product AA. However, all but one product, CC, satisfied the USP requirement of a minimum of $75 \%$ release within $30 \mathrm{~min}$.

\section{Pharmaceutical equivalence}

If a particular drug product meets the requirements of USP for dissolution and other in vitro parameters, it gives assurance that the drug will be released satisfactorily from the dosage formulation in vivo and should lead to good bioavailability. Although most of the tested products met compendial standards, including content uniformity, disintegration and dissolution rates, all the products cannot be classified as pharmaceutical equivalents. Pharmaceutical equivalents are those drug products in 
identical dosage forms that contain identical amounts of the same active drug and that meet identical compendial or other applicable standards, including potency, content uniformity, disintegration time and dissolution rate. Hence artesunate products A, C, D, E and $\mathrm{H} 1$ were pharmaceutical equivalents as were amodiaquine samples $\mathrm{AA}, \mathrm{BB}, \mathrm{DD}$ and EE.

\section{CONCLUSION}

The detection of substandard and overpacked artesunate tablets brands and the observation that all the products tested had different dissolution profiles and disintegration rates imply that they were not pharmaceutical equivalents. Since pharmaceutical equivalence is a basic requirement (among other factors) for substitution when prescribing and/or dispensing drugs, this study shows that caution should be applied in substituting generic brands of artesunate and amodiaquine in the market in southwestern Nigeria.

\section{REFERENCES}

1. Olumese P. Global Antimalarial Drug Policy Database. Antimalarial Treatment Policies for $P$. falciparum and $P$. vivax by Country in WHO Africa and Eastern Mediterranean Region [Accessed 9 August 2007]. Available from: http://www.who.int/malaria/treatmentpolicies.ht ml.

2. Shunmay $Y$, Wirichada $P$, lan M. H, Anne J.M, and Nicholas J.W. Antimalarial drug resistance, artemisinin-based combination therapy, and the contribution of modeling to elucidating policy choices. Am J Trop Med Hyg, 2004; 71 (suppl 2): 179-186

3. Na-Bangchang $K$, Karbwang J, Congpoung $K$, Thanavibul $A$ and Ubalee $R$. Pharmacokinetic and bioequivalence evaluation of two generic formulations of oral artesunate. Eur. J. Clin. Pharm. 1998; 53: 375-376.

4. White, NJ. Assessment of the pharmacodynamic properties of antimalarial drugs in vivo. Antimicrob. Agents Chemother. 1997; 41: 1413-1422.

5. Alter HK, Newton NP, Green MD. Characterization of counterfeit artesunate antimalarial tablets from Southeast Asia. Am. J. Trop. Med. Hyg. 2006; 75: 804- 811

6. Davies B. Malaria, science, and social responsibility. Scientist 2005; 19: 42-43.

7. White NJ. Antimalarial drug resistance. J. Clin. Invest. 2004; 113: 1084-1092.

8. Aldhous P. Murder by medicine. Nature 2005; 434: 132-136.

9. Dondorp AM, Newton PN, Mayxay M. Fake antimalarials in Southeast Asia are a major impediment to malaria control: multinational crosssectional survey on the prevalence of fake antimalarials. Trop. Med. Int. Health 2004; 9: 1241-1246.

10. Federal Standard Number 595 Color Specification. Fed. Std-595B Specification Reference Site. Fed-Specs.com. [Accesssed 21 January 2008]. Available from http://www.fed-std595.com/FS-595-Paint-Spec.html.

11. British Pharmacopoeia Vol 1, London Her Magcsty's Stationery Office, 2001;Appendix $X I I G$

12. International Pharmacopoeia. Ed 3 Vol. 1-5. Quality Specifications for Pharmaceutical Substances. WHO, Geneva, 2009; $p 228$

13. United States Pharmacopoeia, Revision 31/NF26, Volume 2, USP Convention Inc. Rockville, Md, 2008; $p 1406$

14. Magnus A, Kateligine De $C$, Jacqueline DV. Quality control of active ingredients in artemisinin derivative antimalarials within Kenya and $D R$ Congo. Trop. Med. Int. Health 2007; 12: 68-74

15. Newton $P$, Suputtamongkol $Y$, Teja-isavadharm $P$, Pukrittayakamee $S$, Navaratnam $V$ Bates $I$. Antimalarial bioavailability and disposition of artesunate in acute falciparum malaria. Antimicrob. Agents Chemother. 2000; 44: 972977.

16. National Antimalaria Treatment Policy (NATP) and National Malaria and Vector Control Policy Division (NMVCP), Federal Ministry of Health, Abuja, Nigeria. Nov. 2004.

17. British Pharmacopeia I \& II. London: Her Majesty's Stationery Office, 2001. 